\title{
Preparation and characterization of carbon nano-sheet powders*
}

\author{
Yang Wubao ${ }^{1 * *}$, Zhao Zhen ${ }^{2}$, Fang Songhua ${ }^{3}$, Wang Yong ${ }^{1}$, Yang Size $^{3}$ and \\ Lin $\mathbf{L i}^{1}$
}

${ }^{1}$ School of Electromechanical Engineering, China University of Petroleum, Beijing 102249, China

${ }^{2}$ School of Chemical Science and Engineering, China University of Petroleum, Beijing 102249, China

${ }^{3}$ Institute of Physics, Chinese Academy of Sciences, Beijing 100080, China

\begin{abstract}
Carbon nanosheet films were deposited on Al substrates by using plasma assisted chemical vapor deposition (PACVD) technique. And after being peeled off from Al substrates, carbon nanosheet powders (CNSPs) were obtained. In Raman spectrum of carbon film, there was a strong and broadened peak at about $1,580 \mathrm{~cm}^{-1}$, indicating a carbon diamond-like film. Atomic force microscope image showed that the carbon diamond-like film had a grain size less than $100 \mathrm{~nm}$, and its surface roughness Ra was $17.95 \mathrm{~nm}$ in an area of $5 \times 5 \mu \mathrm{m}^{2}$. The CNSPs were irregular sheets with curly edges and a length of several micrometers to several hundreds of micrometers. The BET surface area of CNSPs was $6.66 \mathrm{~m}^{2} / \mathrm{g}$ with no micro-pore present, which was confirmed by $\mathrm{N}_{2}$ adsorption-desorption characterization. In the adsorption testing, when the relative pressure $\mathrm{p} / \mathrm{p}_{0}$ was higher than 0.3 , the adsorption behavior did not follow the Langmuir equation. The addition of CNSPs to carbon black (catalyst support) could improve hydrodesulfurization performance of carbon supported Ni-W catalysts for diesel oil.
\end{abstract}

Key words: Plasma assisted chemical vapor deposition, carbon nanosheet powder, $\mathrm{N}_{2}$ adsorption/ desorption, hydrodesulfurization

\section{Introduction}

Nano-powders or nano-particles are widely used in metallurgical, mechanical, medical, chemical, food, agricultural, paint, electronic, and energy source industries. Nano-powders possess many excellent properties that can meet some specific requirements, thereby attracting many researchers' attention. Normally, the shape of nano-powders is spherical, but several kinds of nano-powders with special shapes were developed for specific applications, such as nanotubes, nanowires, nanorods, nanoribbons, nanobelts, and nanosheets (Chen et al, 2004; Lee et al, 2003; Lee and Kim 2004; Li et al, 2003; 2004; Kearns, 2004; Tsai, 2004; Qiu et al, 2004). Nanosheet powders (NSPs) can be prepared by the following procedure: 1) Thin films were formed on suitable substrates by deposition; 2) The thin films were peeled off from substrates and NSPs were obtained. NSPs are characterized by thin sheet structure, having a thickness of the nanometer order and a length of several micrometers to several hundreds of micrometers, which can be designed according to practical requirements. Moreover, NSPs have some special characteristics, and especially their surface area, structure, and composition can be controlled.

Carbon powder is one of the most useful carbon materials. Carbon black can be used as ink and electric additives;

* Supported by the Venture Fund of PetroChina Company Limted (050511-3-4)

** Corresponding author: email: ywbbms@yahoo.com.cn

Received June 7, 2007 and diamond powders are important abrasives and mould materials. Moreover, carbon powders have been developed as anode materials for lithium ion secondary cell, and catalyst support for chemical industry.

Carbon powders may be porous or solid material, with variable structures and sizes (Andreyev et al, 2002; Hasegawa et al, 2004; Hirata et al, 2004; Kuzuya et al, 2002; Kwon et al, 2004; Li et al, 2001; Perkson et al, 2003). In this paper, based on the idea of NSP, carbon nanosheet powders (CNSPs) were prepared by using the plasma assisted chemical vapor deposition (PACVD) technique. The surface characteristics, powder structure, surface area of CNSPs were analyzed, and as a catalyst support, its effect on catalytic performance of carbon supported $\mathrm{Ni}-\mathrm{W}$ catalysts was also investigated.

\section{Experimental}

\subsection{Preparation of CNSPs}

CNSPs were prepared in two steps. Firstly, carbon films were deposited on Al substrates by using the PACVD technique. Then the films were peeled off from the substrate to obtain CNSPs. The deposition conditions are as follows: gas pressure: $10 \mathrm{~Pa}$; active precursors: methane and hydrogen with a molar ratio of $\mathrm{CH}_{4}$ to $\mathrm{H}_{2}$ of 3; deposition temperature: room temperature; and the plasma was produced under $2 \mathrm{kV}$ direct current voltages.

After deposition, the films were peeled off by mechanical scrubbing with silk cloth, and the CNSPs were obtained. 


\subsection{Characterization of CNSPs}

Before being peeled off from the substrates, the thickness of the thin solid film was observed with an optical microscope (DH-150), and its surface morphology was characterized with an atomic force microscope (AFM, Digital Instruments, Nanoscope IIIA). The structure of carbon in this solid film was investigated by Raman spectroscopy (Stex-1403).

After being peeling off from the substrates, the characteristics of CNSPs were investigated with a scanning electron microscope (SEM, Hitachi S-4200) and their surface area was measured by a $\mathrm{N}_{2}$ absorption/desorption method (ASAP 2020M).

The active components of $\mathrm{Ni}$ and $\mathrm{W}$ were loaded on the carbon support by the incipient wetness impregnation with an aqueous solution of an appropriate amount of ammonium metatungstate hydrate $\left[\left(\mathrm{NH}_{4}\right)_{6} \mathrm{~W}_{12} \mathrm{O}_{39} \cdot \mathrm{H}_{2} \mathrm{O}\right]$ and nickel nitrate hexahydrate $\left[\mathrm{Ni}\left(\mathrm{NO}_{3}\right)_{2} \cdot 6 \mathrm{H}_{2} \mathrm{O}\right]$. Here, the carbon support was carbon black or the mixture of carbon black and carbon nanosheet powders. After impregnation, the prepared samples were dried in a microwave oven for $20 \mathrm{~min}$. Finally, the samples were calcined at $823 \mathrm{~K}$ for $4 \mathrm{~h}$. The compositions of catalyst samples are listed in Table 1 .

Table 1 The compositions of catalyst samples

\begin{tabular}{ccccc}
\hline \multirow{2}{*}{ Catalyst sample } & \multicolumn{4}{c}{ Composition, \% } \\
\cline { 2 - 5 } & Carbon black & CNSP & NiO & $\mathrm{WO}_{3}$ \\
\hline 1 & 66.5 & 0 & 3.5 & 30 \\
2 & 63.2 & 3.3 & 3.5 & 30 \\
\hline
\end{tabular}

The catalytic performance was evaluated in a highpressure fixed-bed reactor pilot unit. In the activity evaluation experiments, $2 \mathrm{~g}$ of 40-60 mesh catalyst mixed with $2 \mathrm{~g}$ of 40-60 mesh silica particles were packed into a $8 \mathrm{~mm}$ i.d. stainless steel tubular reactor between two 15-cm layers of 40-60 mesh silica particles. All catalysts were presulfided for $6 \mathrm{~h}$ with $2 \mathrm{wt} \% \mathrm{CS}_{2}$-cyclohexane mixture under the conditions of LHSV (liquid hourly space velocity) of $1.0 \mathrm{~h}^{-1}$, temperature of $593 \mathrm{~K}$, total pressure of $4 \mathrm{MPa}$ and a ratio of $\mathrm{H}_{2}$ to cyclohexane of $600 \mathrm{~cm}^{3} / \mathrm{cm}^{3}$. Hydrodesulfurization of diesel oil was carried out under the conditions of 623 $\mathrm{K}, 5.0 \mathrm{MPa}, 1.0 \mathrm{~h}^{-1}$ and $\mathrm{H}_{2} /$ liquid ratio $600 \mathrm{~cm}^{3} / \mathrm{cm}^{3}$. The catalytic activity under investigation was estimated by the hydrodesulfurization efficiency (HDS efficiency). The diesel oil used was a blend of straight run diesel oil and FCC diesel oil and its properties are tabulated below.

Table 2 Properties of diesel oil used

\begin{tabular}{cccc}
\hline Density, g/cm & IBP, K & $\mathrm{T}_{95}, \mathrm{~K}$ & Sulfur content, $\mu \mathrm{g} / \mathrm{g}$ \\
\hline 0.8195 & 427 & 638 & 432.5 \\
\hline
\end{tabular}

\section{Results and discussion}

\subsection{Carbon structure}

The structure of carbon film (before being peeled off) was investigated by Raman spectroscopy. A strong G peak was widened evidently and a very weak D peak was detected, as shown in Fig. 1.

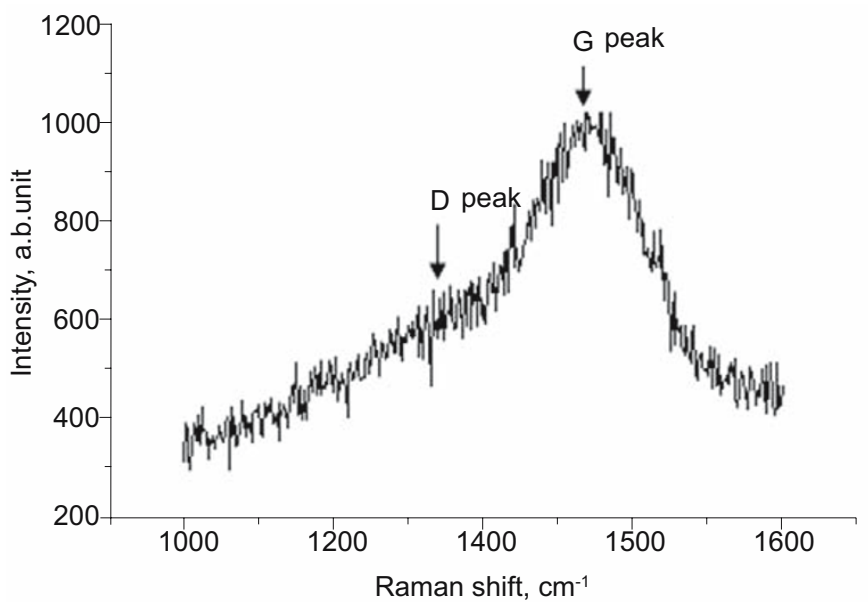

Fig. 1 Raman spectrum of carbon nanosheet film

For amorphous carbon, there are two peaks commonly referred as $\mathrm{D}\left(1,358 \mathrm{~cm}^{-1}\right)$ and $\mathrm{G}\left(1,580 \mathrm{~cm}^{-1}\right)$ peaks in the Raman spectrum (Robertson, 2002; Shi et al, 2001; Yang et al, 2002). If carbon solids are non-crystalline and carbon atoms are fundamentally in the $s p^{3}$ bonding state, there would be only a broadened G peak. The Roman spectrum (Fig. 1) shows that the carbon film prepared is non-crystalline and dominated by $\mathrm{sp}^{3}$ bonding, indicating the film being diamondlike carbon film.

\subsection{Surface analysis of diamond-like carbon film}

Before being peeled off, the surface morphology of diamond-like carbon film was tested by an atomic force microscope. Fig. 2 indicates that the grains, which form the nano carbon thin film are generally very much less than 100 $\mathrm{nm}$ in diameter. The rough surface $\mathrm{Ra}$ is $17.95 \mathrm{~nm}$ and the distance from top to bottom of the film is $250.95 \mathrm{~nm}$ in an area of $5 \times 5 \mu \mathrm{m}^{2}$ of film.

The thickness of the deposited carbon film was estimated by optical microscopy to be about $900 \mathrm{~nm}$. The deposition weight per unit area of the carbon film was $0.252 \mathrm{mg} / \mathrm{cm}^{2}$, which was determined by weighting the sample before and after peeling off. Therefore the density of deposits was about $2.8 \mathrm{~g} / \mathrm{cm}^{3}$. The surface area of prepared CNSPs was $0.8 \mathrm{~m}^{2} / \mathrm{g}$ when side area and surface roughness are not considered; and the real surface area would be larger than $6.0 \mathrm{~m}^{2} / \mathrm{g}$ when considering the surface roughness.

\subsection{Morphology of carbon powders}

The image (Fig. 3) shows the irregular sheet-like shape of the carbon nano powders. These sheets prepared ranged from several micrometers to hundreds of micrometers, with curly edges. 


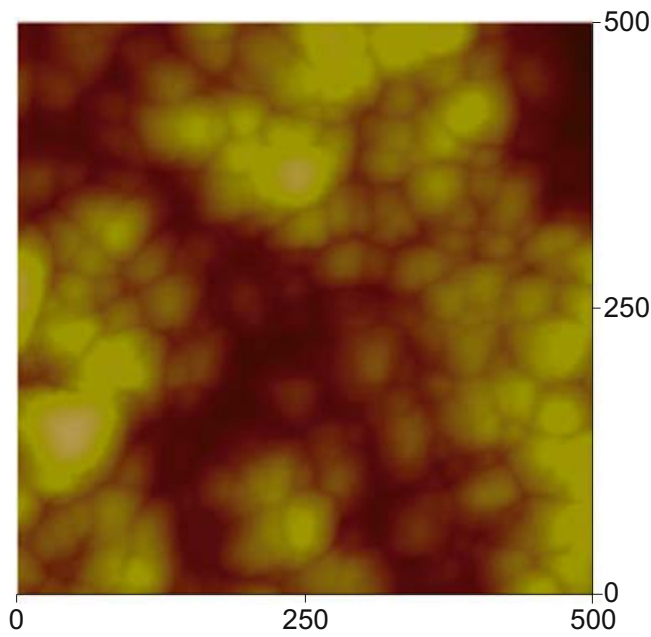

Fig. 2 AFM image of the deposited carbon film

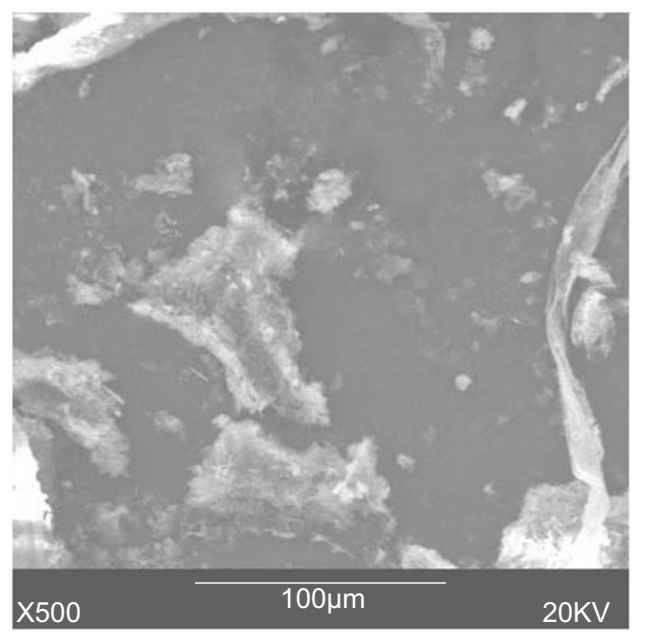

Fig. 3 SEM photograph of the carbon nano sheet powders

\subsection{Adsorption/desorption characteristics of CNSPs}

There were no micro-pores in these powders, as demonstrated by $\mathrm{N}_{2}$ adsorption-desorption characterization. Fig. 4 shows the nitrogen adsorption-desorption properties of the CNSPs. The BET surface area calculated in the range $p / p_{0}$ of 0 to 0.3 is $6.66 \mathrm{~m}^{2} / \mathrm{g}$.

$\mathrm{N}_{2}$ adsorption-desorption characteristics of CNSPs did not follow the conventional Langmuir equation when the relative pressure was larger than 0.3. A possible explanation for this is that: At the initial stage of adsorption, $\mathrm{N}_{2}$ isotherms displayed a normal Langmuir-type adsorption behavior up to a relative pressure of about 0.3 . Once the surface of CNSPs was covered by $\mathrm{N}_{2}$ molecules to a specified level, the adsorbed gases were agglomerated to become blebs, which spanned the peaks between grains, therefore the $\mathrm{N}_{2}$ molecules in the valley decreased. Higher $\mathrm{p} / \mathrm{p}_{0}$ would result in forming more blebs, thereby producing buoyant force. The mechanism is schematically shown in Fig. 5. The other reason is that, there may be exit impurities in these samples and desorption would occur when the $\mathrm{p} / \mathrm{p}_{0}$ was greater than 0.3 .

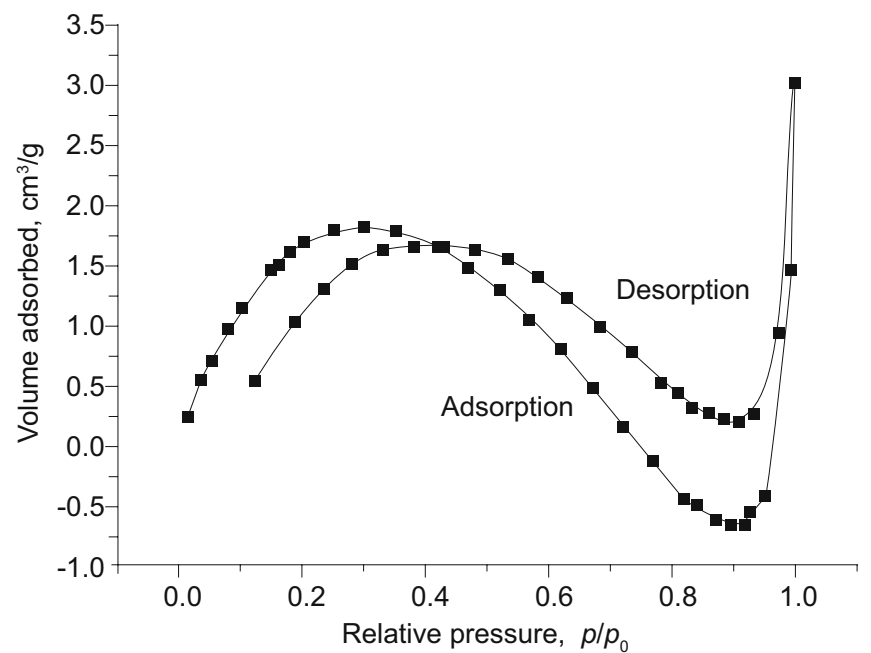

Fig. 4 Nitrogen adsorption-desorption isotherms

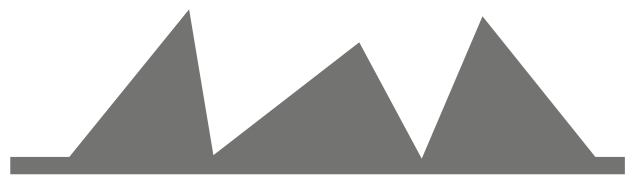

(a) The original CNSPs

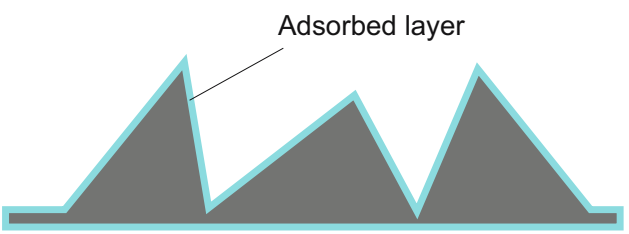

(b) $p / p_{0}<0.3$

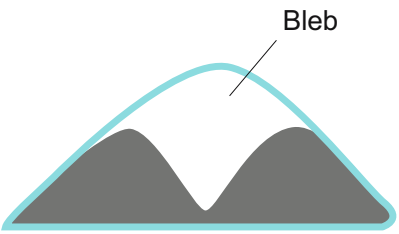

(c) $p / p_{0}>0.3$

Fig. 5 The schematic mechanism of $\mathrm{N}_{2}$ adsorption-desorption over CNSPs

\subsection{Effect of CNSPs on desulfurization performance of carbon-supported $\mathrm{Ni}-\mathrm{W}$ catalysts}

After hydrodesulfurization over Samples 1 and 2, the sulfur content of diesel oil reduced from 432.5 parts per million to 55.4 and 48.5 parts per million, and the corresponding desulfurization efficiencies were $87.1 \%$ and $88.7 \%$, respectively. Therefore, the resultant desulfurization performance was improved significantly when the CNSPs were added to carbon black. The catalytic performance of carbon-supported catalysts is listed in Table 3.

Compared with carbon black, CNSPs, as a catalyst support have high strength, which enables the catalyst to work efficiently and not to be broken into smaller particles in the 
Table 3 Catalytic performance of carbon-supported catalysts

\begin{tabular}{cccc}
\hline \multirow{2}{*}{ Catalyst sample } & \multicolumn{2}{c}{ Sulfur content of diesel oil, $\mu \mathrm{g} / \mathrm{g}$} & HDS efficiency, \% \\
\cline { 2 - 3 } 1 & Before desulfurization & After desulfurization & $87.1 \%$ \\
& 432.5 & 55.4 & $88.7 \%$ \\
\hline
\end{tabular}

reaction process. Their sheet structure prevents the CNSPssupported catalyst from agglomerating and makes the catalyst disperse readily. Moreover, the active components could be loaded on the outer surface of CNSPs uniformly because there are no inner pores in CNSPs, which can improve the contact between feed oil and catalyst active components. The CNSPsupported catalysts have excellent catalytic performance due to these special properties of CNSPs.

\section{Conclusions}

1) A new type of powders, carbon nanosheet powder (CNSP) was prepared by plasma assisted chemical vapor deposition technique.

2) The CNSPs were irregular sheets, with a length of about $10-500 \mu \mathrm{m}$, and curly edges. The sheets consisted of nanometer grains. Raman spectrum indicated that the carbon atoms in CNSPs were mainly in the $\mathrm{sp}^{3}$ bonding state. $\mathrm{N}_{2}$ adsorption-desorption test showed that the BET surface area of the CNSPs was $6.66 \mathrm{~m}^{2} / \mathrm{g}$. When relative pressure was larger than 0.3 , the adsorption-desorption isotherms did not follow the Langmuir equation.

3) The addition of CNSPs to carbon black (as a catalyst support) could improve desulfurization performance of carbon-supported Ni-W catalyst for diesel oil.

\section{References}

Andreyev A, Akaishi M and Golberg D. Synthesis of nanocrystalline nitrogen-rich carbon nitride powders at high pressure. Diamond and Related Materials. 2002. 11(12): 1885-1889

Chen B J, Sun X W, Xu C X, et al. Growth and characterization of zinc oxide nano/micro-fibers by thermal chemical reactions and vapor transport deposition in air. Physica E: Low-dimensional Systems and Nanostructures. 2004. 21(1): 103-107

Hasegawa T, Mukai S R, Shirato Y, et al. Preparation of carbon gel microspheres containing silicon powder for lithium ion battery anodes. Carbon. 2004. 42(12-13): 2573-2579

Hirata A, Igarashi M and Kaito T. Study on solid lubricant properties of carbon onions produced by heat treatment of diamond clusters or particles. Tribology International. 2004. 37(11-12): 899-905

Kearns M. Development and applications of ultrafine aluminium powders. Materials Science and Engineering A. 2004. 375-377, $120-126$

Kuzuya C, Hayashi Y and Motojima S. Preparation of carbon microcoils involving the decomposition of hydrocarbons using PACT (plasma and catalyst technology) reactor. Carbon. 2002. 40(7): 1071-1077

Kwon O J, Jung Y S, Kim J K, et al. A simple preparation method for spherical carbons and their anodic performance in lithium secondary batteries. Journal of Power Sources. 2004. 125(2): 221-227

Lee D W and Kim B K. Nanostructured $\mathrm{Cu}-\mathrm{A}_{12} \mathrm{O}_{3}$ composite produced by thermochemical process for electrode application. Materials Letters. 2004. 58(3-4): 378-383

Lee D W, Won J H and Shim K B. Low temperature synthesis of $\mathrm{BaCeO}_{3}$ nano powders by the citrate process. Materials Letters. 2003. 57(22-23): 3346-3351

Li J G, Gao L and Guo J K. Mechanical properties and electrical conductivity of TiN- $\mathrm{A}_{12} \mathrm{O}_{3}$ nanocomposites. Journal of the European Ceramic Society. 2003. 23(1): 69-74

Li X K, Liu L and Shen S D. The influence of starting materials on the structure of ultrafine carbon powders. Carbon. 2001. 39(15): 2335-2338

Li Y Z, Lee N H, Lee E G, et al. The characterization and photocatalytic properties of mesoporous rutile $\mathrm{TiO}_{2}$ powder synthesized through self-assembly of nano crystals. Chemical Physics Letters. 2004. 389(1-3): 124-128

Perkson A, Leis J, Arulepp M, et al. Barrel-like carbon nanoparticles from carbide by catalyst assisted chlorination. Carbon. 2003. 41(9): 1729-1735

Qiu J S, Li Y F, Wang Y P, et al. Preparation of carbon-coated magnetic iron nanoparticles from composite rods made from coal and iron powders. Fuel Processing Technology. 2004. 86(3): 267-274

Robertson J. Diamond-like amorphous carbon. Materials Science and Engineering R. 2002. 37(1): 129-281

Shi J R, Shi X, Sun Z, et al. Resonant Raman studies of tetrahedral amorphous carbon films. Diamond and Related Materials. 2001. 10(1): 76-81

Tsai M S. Powder synthesis of nano grade cerium oxide via homogenous precipitation and its polishing performance. Materials Science and Engineering B. 2004. 110(1): 132-134

Yang W B, Lu F X and Cao Z X. Growth of nanocrystalline diamond protective coatings on quartz glass. Journal of Applied Physics. 2002. 91 (12): 10068-10063

(Edited by Sun Yanhua) 